\title{
Molecular recognition of flunarizine dihydrochloride and $\beta$-cyclodextrin inclusion complex by NMR and computational approaches
}

Santosh Kumar Upadhyay ${ }^{1 *}$ (D) and Syed Mashhood Ali $^{2^{*}}$

\begin{abstract}
Background: Flunarizine dihydrochloride (FLN) is used in the prophylactic treatment of migraine, vertigo, occlusive peripheral vascular disease and epilepsy. Cyclodextrins (CDs) are chiral, truncated cone shaped macrocycles known for their inner hydrophobic and outer hydrophilic site. They form complexes with hydrophobic drug molecules and enhance the solubility and bioavailability of such compounds by enhancing drug permeability through mucosal tissues. NMR spectroscopy and computational docking have been recognized as an important tool for the interaction study of CDs-drug inclusion complexes in solution state.

Results: The structural assignments of FLN and $\beta-C D$ protons were determined by ${ }^{1} \mathrm{H} N M R$ and $2 \mathrm{D}^{1} \mathrm{H}^{1} \mathrm{H}$ COSY NMR spectroscopy. ${ }^{1} \mathrm{H}$ NMR spectroscopic studies of FLN, $\beta-C D$ and their mixtures confirmed the formation of $\beta$-CD-FLN inclusion complex in solution. ${ }^{1} \mathrm{H}$ NMR titration data for $\beta-C D-F L N$ inclusion complex showed 1:1 stoichiometry, an association constant of $K_{a}=157 \mathrm{M}^{-1}$ and change in Gibbs free energy of $\Delta \mathrm{G}=-12.65 \mathrm{~kJ} \mathrm{~mol}^{-1}$. The binding constant of the $\beta$-CD inclusion complex with two nearly similar structures, FLN and cetirizine dihydrochloride, were compared. Two-dimensional ${ }^{1} \mathrm{H}-{ }^{1} \mathrm{H}$ ROESY spectral data and molecular docking studies showed the modes of penetration of the aromatic rings from the wider rim side into the $\beta-C D$ cavity. The possible geometrical structures of the $\beta-C D-F L N$ inclusion complex have been proposed in which aromatic rings protrude close to the narrower rim of the $\beta-C D$ truncated cone.

Conclusion: NMR spectroscopic studies of FLN, $\beta-C D$ and FLN: $\beta-C D$ mixtures confirmed the formation of 1:1 inclusion complex in solution at room temperature. Two-dimensional ${ }^{1} \mathrm{H}-{ }^{1} \mathrm{H}$ ROESY together with molecular docking study confirmed that the F-substituted aromatic ring of FLN penetrates into $\beta$-CD truncated cone and the tail of aromatic rings were proximal to narrower rim of $\beta-C D$. The splitting of aromatic signals of FLN in the presence of $\beta$-CD suggests chiral differentiation of the guest FLN by $\beta-C D$.
\end{abstract}

Keywords: Flunarizine dihydrochloride, $\beta$-Cyclodextrin, Inclusion complex, NMR spectroscopy, Molecular recognition, ROESY, Molecular docking

\section{Introduction}

Migraine is a severe headache often unilateral, commonly accompanied by nausea, vomiting, and extreme sensitivity to sound and light. Flunarizine dihydrochloride (FLN) is a large hydrophobic fluorinated piperazine derivative, used in the prophylactic treatment of

\footnotetext{
*Correspondence: skupadhyay@msn.com; skupadhyay@igib.res.in; smashhoodali@gmail.com

${ }^{1}$ CSIR-Institute of Genomics \& Integrative Biology, New Delhi 110020, India

${ }^{2}$ Department of Chemistry, Aligarh Muslim University, Aligarh 202002, UP, India
}

migraine, vertigo, occlusive peripheral vascular disease and epilepsy [1]. FLN (Fig. 1a) is a di-fluorinated derivative of cinnarizine and a poorly water-soluble drug. FLN is a selective calcium entry blocker with calmodulin binding properties and histamine $\mathrm{H}_{1}$ blocking activity. It is also known to prevent hepatitis $C$ virus membrane fusion in a genotype-dependent manner [2] and to suppress endothelial angiopoietin-2 in a calcium-dependent fashion in sepsis [3]. FLN is reportedly effective against hepatitis $\mathrm{C}$ virus activity, preferably for the genotype 2 viruses [4]. 


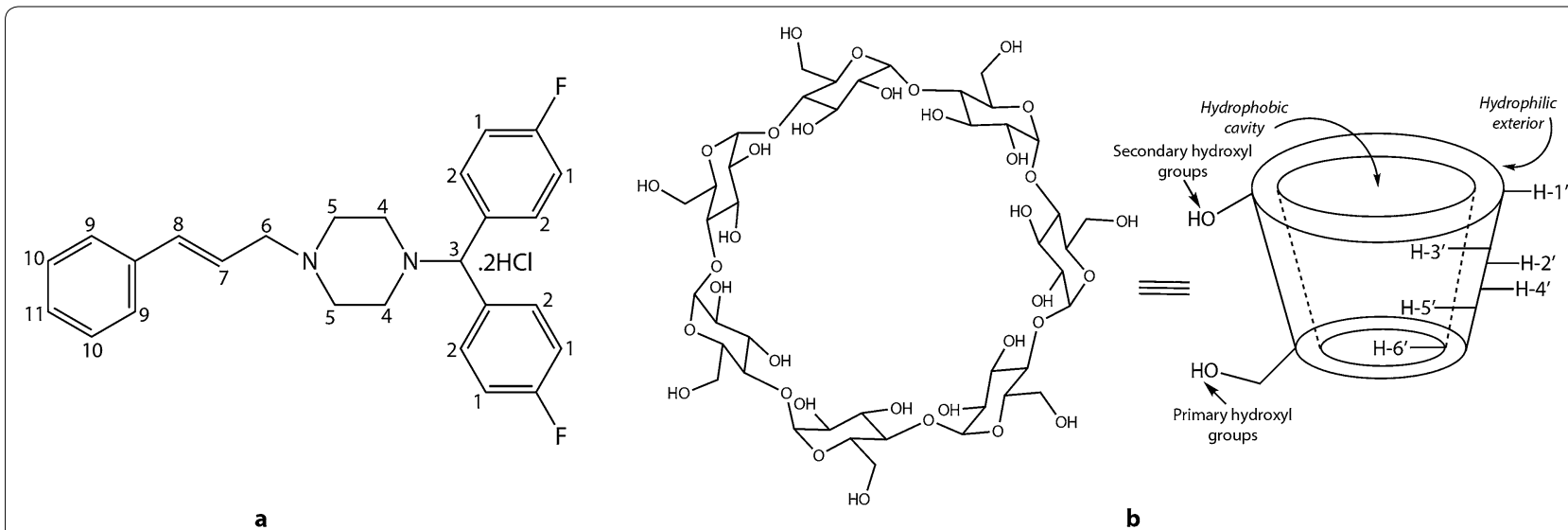

Fig. 1 Structural representation of $\mathbf{a}$ FLN (guest) ligand and $\mathbf{b} \beta-C D$ (host) macrocycle [Source Adopted from "NMR and molecular modelling studies on the interaction of fluconazole with $\beta$-cyclodextrin" by S.K. Upadhyay et al. (2009) Chemistry Central Journal 3:9]

Cyclodextrins (CDs) or cycloamyloses are truncated cone-shaped macrocycles (Fig. 1b) produced from starch through enzymatic degradation. CDs are a family of cyclic oligosaccharides and have been studied extensively as supramolecular hosts $[5,6]$. The three common CDs are crystalline, homogeneous, nonhygroscopic substances, consisting of six $(\alpha-)$, seven $(\beta-)$, and eight $(\gamma-)$ $D$-glucose units, respectively, linked by $\alpha-D-(1 \rightarrow 4)$ glycosidic bonds (Fig. 1b) $[5,6]$. The glucose residue in CD has $4 \mathrm{C}_{1}$ (chair) conformation [5]. The primary hydroxyl groups $(\mathrm{n})$ are located at the narrower rim whereas the wider rim is lined with secondary hydroxyl groups (2n). The outer surfaces of the CDs are highly hydrophilic due to the presence of a large number of hydroxyl groups but the central cavities are relatively hydrophobic (Fig. 1b). The outer dimension of these three common CDs are constant at $0.78 \mathrm{~nm}$ but their inner dimensions are variable, being $0.57 \mathrm{~nm}$ for $\alpha-, 0.78 \mathrm{~nm}$ for $\beta$-, and $0.95 \mathrm{~nm}$ for $\gamma$-CD respectively [6]. The $\mathrm{H}-3^{\prime}$ and $\mathrm{H}-5^{\prime}$ protons of these $\mathrm{CDs}$ are located in the hydrophobic central cavity whereas other protons $\left(\mathrm{H}-1^{\prime}, \mathrm{H}-2^{\prime}, \mathrm{H}-4^{\prime}\right.$ and $\left.\mathrm{H}-6^{\prime}\right)$ are located at the outer surface (Fig. 1b), which is relatively hydrophilic. These properties facilitate their aqueous solubility and ability to encapsulate hydrophobic moieties within their central cavities through non-covalent interactions. CDs form host-guest inclusion complexes upon penetration of guest molecule in the central cavity of host CDs.

CDs are extensively studied in various areas of chemistry including macrocyclic [7], supramolecular [8, 9], agro [10], click [11], analytical [12], chromatography $[13,14]$, sugar-based surfactants [15], foods [16], catalysis $[17,18]$, membranes [19], textiles [20], cosmetics [21, $22]$, fragrance and aromas [23, 24], enzyme technology [25], pharmacy and medicine [26-28], microencapsulation [29], nanotechnologies [30-33], remediation
[34], decontamination [35] and biotechnology [36]. The unique properties of CDs allow their various applications in many areas [37-40]. CDs are used to prepare inclusion complexes with pharmaceuticals for biomedical applications and biomedicine [22, 31, 36-38]. CDs are widely used in food industry as food additives, stabilizing flavours, to remove undesirable compounds such as cholesterol, and also as agents to avoid microbiological contaminations in the food [16]. CDs can be used to enhance solubility, bioavailability and stability of pharmaceuticals [41-43]. Upon complexation with pharmaceutical compounds, CDs form inclusion complexes with the ability to alter the physiochemical properties of the complexed drug. Various drugs such as nimesulide, omeprazole, piroxicam, mitomycin, diclofenac sodium, indomethacin and others complexed with CDs are approved and available in the market [42]. Inclusion complexes with dimethyl- $\beta-C D$ are used in the preparation of vaccine Deptacel (Sanofi Group, Pasteur) for protection against diphtheria, tetanus and pertussis. CDs are also used to stabilize sensitive substances to light or oxygen [44], proteins [45], nanoparticles [46], and add value addition of taste and colour of toothpaste [44].

Among various known spectroscopic methods such as Ultraviolet-visible (UV-Vis), Fourier-transform infrared (FTIR) spectroscopy for the studies of inclusion complexes between host CDs and guest molecules, Nuclear Magnetic Resonance (NMR) spectroscopy is considered as one of the most significant analytical tool for understanding the interaction between host and guest molecules [47]. This technique provides not only the structural assignments of host and guest molecules but also data on the inclusion complex formation. Further NMR spectroscopy could also offer valuable information on chiral recognition or chiral discrimination or both [47-49]. NMR titration data can be 
used to determine the stoichiometry and association constant of the host-guest complexes [50-52].

Two-dimensional (2D) NMR method such as ${ }^{1} \mathrm{H}_{-}{ }^{1} \mathrm{H}$ COSY (COrrelation SpectroscopY) is a useful technique, which provides information on the ${ }^{1} \mathrm{H}$ signals arising from neighbouring protons connected through bonds and protons signals emerging from up to 4 bonds can be captured. Two-dimensional ${ }^{1} \mathrm{H}-{ }^{1} \mathrm{H}$ Rotating-frame Overhauser Effect SpectroscopY (ROESY) has been found to be useful for the investigation of the interaction between $\mathrm{CD}$ and guest molecule as the Nuclear Overhausser Effect (NOE) cross-peaks are observed between the protons that are close in space even if they are not bonded [47, 50-52]. Two-dimensional ${ }^{1} \mathrm{H}-{ }^{1} \mathrm{H}$ ROESY provides useful information about the location and depth of inclusion of guest molecule into CD cavity [47, 50-52].

The formation of inclusion complex of a guest molecule with CDs results in the ${ }^{1} \mathrm{H}$ chemical shift changes $(\Delta \delta)$ in both the host and guest protons. The inclusion of a molecule inside the hydrophobic cavity of $C D$ is mainly characterized by the chemical shift variation of the $\mathrm{CD}$ protons located inside the central cavity $\left(\mathrm{H}-3^{\prime}\right.$ and $\left.\mathrm{H}-5^{\prime}\right)$, whereas other $\mathrm{CD}$ protons $\left(\mathrm{H}-1^{\prime}, \mathrm{H}-2^{\prime}, \mathrm{H}-4^{\prime}\right.$ and $\left.\mathrm{H}-6^{\prime}\right)$ are less affected. During host-guest inclusion complex formation the guest molecule protons generally show downfield chemical shift changes but sometimes upfield chemical shift changes are also observed [47].

These analytical procedures revealing the structural details of complexes are used in pharmaceutical industries for characterization. In order to understand correct inclusion architecture of interaction between guest FLN and host $\beta$-CD, we report here a high-resolution NMR spectroscopic and computer-based molecular docking study. We describe our results based on the ${ }^{1} \mathrm{H}$ NMR spectral data with chemical shift changes, 2D ${ }^{1} \mathrm{H}$ ${ }^{1} \mathrm{H}$ COSY spectrum for assignment of protons and ${ }^{1} \mathrm{H}$ ${ }^{1} \mathrm{H}$ ROESY spectrum together with molecular docking approaches thus elucidating the structure of the $\beta-C D$ FLN inclusion complex.

\section{Materials and methods \\ Materials}

Flunarizine dihydrochloride (FLN) was a kind gift from Geno Pharmaceutical Ltd. India. $\beta$-cyclodextrin $(\beta-C D)$ was obtained from Geertrui Haest, Cerestar Application Centre, Food \& Pharma Specialities, France. These materials were used as obtained.

\section{NMR spectroscopy}

${ }^{1} \mathrm{H}$ NMR and $2 \mathrm{D}{ }^{1} \mathrm{H}-{ }^{1} \mathrm{H}$ NMR (COSY, ROESY) spectra were recorded on a JEOL $\alpha-500 \mathrm{MHz}$ instrument in $\mathrm{D}_{2} \mathrm{O}$. The sample temperature was maintained at $300 \mathrm{~K}$ during all NMR experiments. The mixing time $\left(\tau_{\text {mix }}\right)$ for
$2 \mathrm{D}{ }^{1} \mathrm{H}_{-}{ }^{1} \mathrm{H}$ ROESY spectra was $500 \mathrm{~ms}$ under the spinlock condition using standard ${ }^{1} \mathrm{H}_{-}{ }^{1} \mathrm{H}$ ROESY pulse sequences. The chemical shift values $(\delta)$ are reported in ppm. No external indicator was used and HDO peak at $4.80 \mathrm{ppm}$ was considered as an internal reference throughout this work. ${ }^{1} \mathrm{H}$ NMR spectra of six samples of mixtures of $\beta-C D$ and FLN with FLN/ $\beta-C D$ molar ratios ranging from 0.2 to 1.8 were recorded. The FLN/ $\beta-C D$ molar ratios were calculated by direct NMR integration of their appropriate signals. The concentration of $\beta-C D$ was kept constant at $10 \mathrm{mM}$ while that of FLN was varied from 2.0 to $18.0 \mathrm{mM}$. Chemical shifts changes $(\Delta \delta)$ were calculated according to the formula: $\Delta \delta=\delta_{(\text {complex })}-\delta_{(\text {free })}$

\section{Molecular docking studies}

Molecular docking studies were performed using Autodock Vina 1.1.2 [53]. Three-dimensional coordinates of $\beta$-CD (PDB Id: 1DMB) were sourced from http://www. rcsb.org/ while FLN was sourced from the UCSF ZINC database (ZINC19360739) [54]. Molecular docking of FLN into $\beta$-CD cavity was carried out following the methods as reported previously [50]. The grid centre of docking coordinates were $\mathrm{x}=-6.89 \AA, \mathrm{y}=-7.65 \AA$ and $\mathrm{z}=4.34 \AA$. The grid dimensions were $54 \AA, 56 \AA$ and $44 \AA$ in $\mathrm{x}, \mathrm{y}$ and $\mathrm{z}$-axes respectively.

\section{Results and discussion}

$2 D^{1}{ }^{1}-{ }^{1} H$ ROESY spectrum of $\beta-C D-F L N$ mixture and structure of the $\beta-C D-F L N$ inclusion complex by NMR and molecular docking approaches

The understanding of host-guest supramolecular structure is important for the pharmaceutical industry for development of drug-CD based new formulations. In order to clearly establish the identity of the aromatic ring involved in complexation between $\beta-C D$ and FLN, a $2 \mathrm{D}{ }^{1} \mathrm{H}-{ }^{1} \mathrm{H}$ ROESY spectrum of the mixture of $\beta-\mathrm{CD}$ and FLN was analyzed. The NMR spectroscopic studies and assignments of $\beta-C D$ and FLN protons are discussed in " ${ }^{1} \mathrm{H}$ NMR spectral assignments and chemical shift change data of $\beta-C D$ " and " $\mathrm{H}$ NMR spectral assignments and chemical shift change data of FLN" sections. Two-dimensional ${ }^{1} \mathrm{H}^{-1} \mathrm{H}$ ROESY spectrum exhibited strong cross-correlation peak between the cavity protons of $\beta-\mathrm{CD}$ and the protons of the F-substituted aromatic ring of FLN thereby confirming the penetration of F-substituted aromatic rings into the $\beta-C D$ cavity. The cross peaks between phenyl ring protons and $\beta-C D$ cavity protons were also observed but these were relatively weak. It is apparent from the $2 \mathrm{D}^{1} \mathrm{H}_{-}{ }^{1} \mathrm{H}$ ROESY spectrum that $\mathrm{H}-1$ exhibited cross peak with only $\mathrm{H}-5^{\prime}$ while $\mathrm{H}-2$ displayed cross peaks with both the $\mathrm{H}-3^{\prime}$ and $\mathrm{H}-5^{\prime}$ protons. The quality of $2 \mathrm{D}{ }^{1} \mathrm{H}-{ }^{1} \mathrm{H}$ ROESY spectrum is not as good as required. Expansions of the parts of the $2 \mathrm{D}$ 
${ }^{1} \mathrm{H}-{ }^{1} \mathrm{H}$ ROESY spectrum showing cross peaks between protons of aromatic rings of FLN and $\beta$-CD cavity protons are shown in Fig. 2. The full $2 \mathrm{D}{ }^{1} \mathrm{H}-{ }^{1} \mathrm{H}$ ROESY spectrum displaying protons of $\beta-\mathrm{CD}$ and FLN and their NOE cross-correlation peaks close to proposed interaction site are presented in Additional file 1: Figure S1.

On the basis of $1: 1$ stoichiometry of the $\beta$-CD-FLN inclusion complex (see "Stoichiometry and association constant of $\beta$-CD-FLN complex" section) and $2 \mathrm{D}{ }^{1} \mathrm{H}-{ }^{1} \mathrm{H}$ ROESY spectral data, it can be inferred that F-containing aromatic ring preferentially enters into the $\beta$-CD cavity to form the inclusion complex. Also, the non-observance of the cross peak between $\mathrm{H}-3^{\prime}$ and $\mathrm{H}-1$ (Fig. 2b) suggested the position of $\mathrm{H}-1$ towards narrower rim side. The penetration from wider rim side would have brought $\mathrm{H}-1$ closer to $\mathrm{H}-3^{\prime}$ also. It appears that there are interactions between the phenyl ring and $\beta-C D$ but the amount is lower compared to complex formed involving F-containing aromatic ring. The penetration of FLN into $\beta-C D$ cavity was reported to be from wider rim side based on $2 \mathrm{D}$ ${ }^{1} \mathrm{H}-{ }^{1} \mathrm{H}$ ROESY results [55] without clear inclusion architecture. The plausible mode of inclusion and structure of the $\beta$-CD-FLN inclusion complex cannot be achieved only from $2 \mathrm{D}^{1} \mathrm{H}^{-}{ }^{1} \mathrm{H}$ ROESY spectral data and therefore, another approach was required. In order to understand the $\beta$-CD-FLN inclusion complex structure, computerbased molecular docking was performed using Autodock Vina 1.1.2 [53]. Molecular docking studies provide us not only the mode of inclusion but also the depth of penetration inside the $\beta-C D$ cavity during complexation process. The best-docked model of $\beta$-CD:FLN complex is shown in Fig. 3. It is evident that the mode of penetration

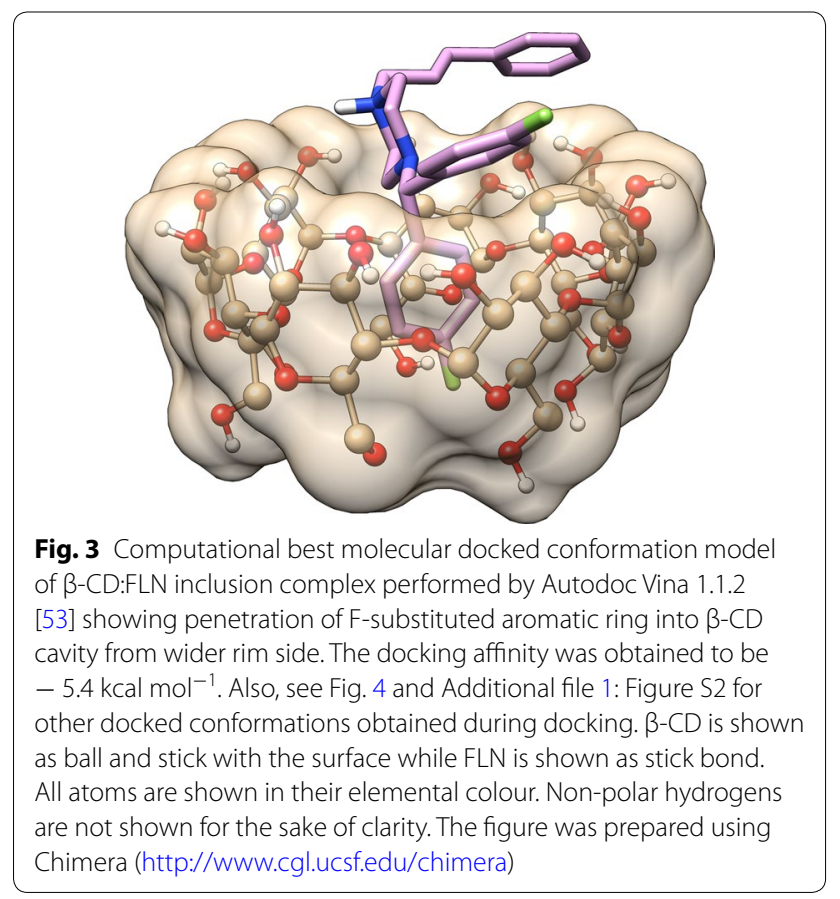

of FLN guest into the $\beta-C D$ cavity was from the wider rim side and similar to $2 \mathrm{D}{ }^{1} \mathrm{H}^{-}{ }^{1} \mathrm{H}$ ROESY results the F-containing aromatic ring participates more favourably than phenyl ring. We compared our result with cetirizine dihydrochloride (CTZ) which has some structural similarity with FLN. CTZ, an antihistamine drug used to treat allergies, formed 1:1 inclusion complexes in which the penetration of CTZ into the $\beta$-CD cavity was from wider

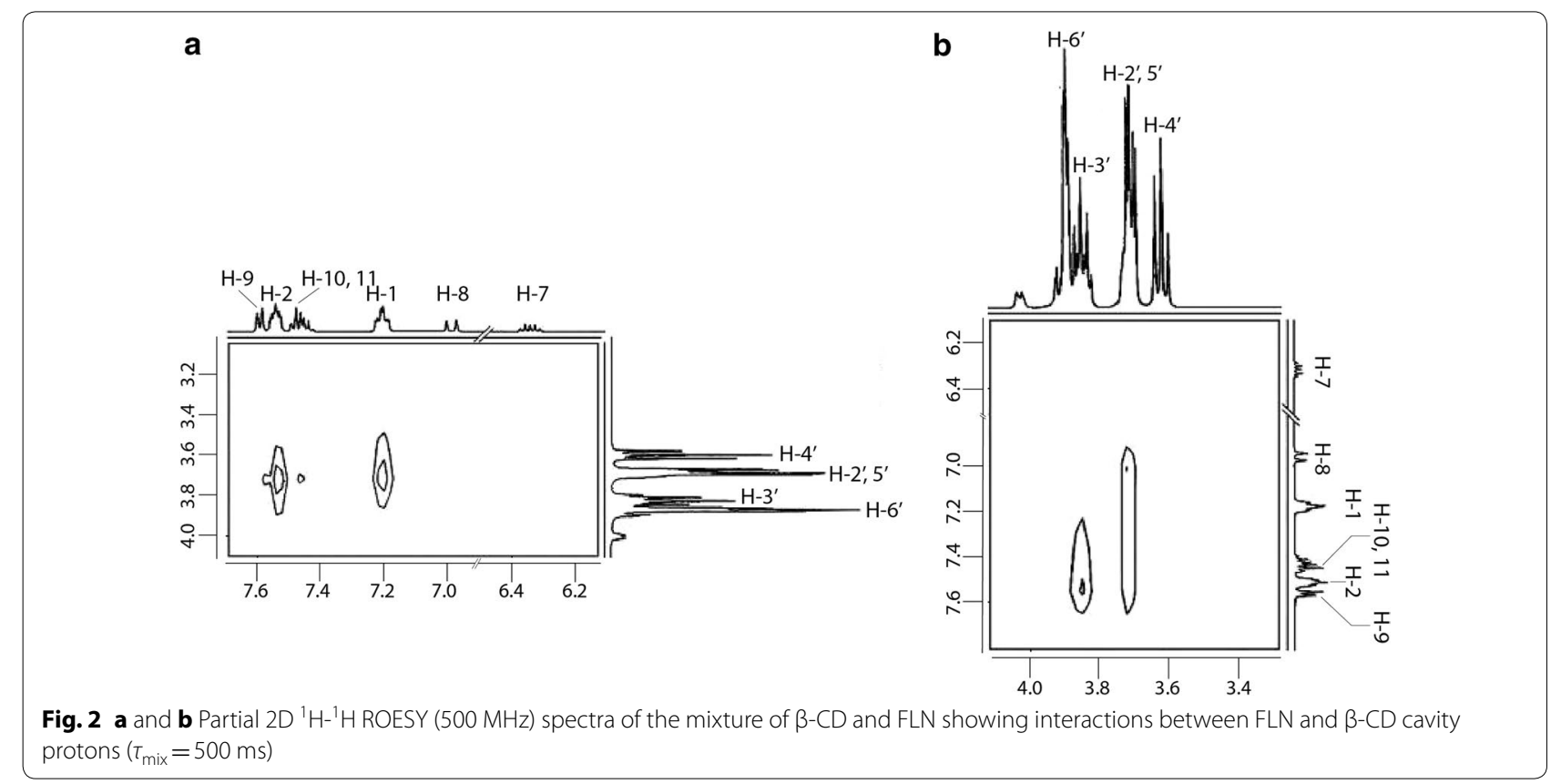


rim side [56]. Similarly our $2 \mathrm{D}{ }^{1} \mathrm{H}_{-}{ }^{1} \mathrm{H}$ ROESY and molecular docking approach together provide information about the penetration of FLN from the wider rim side of the $\beta$-CD cavity [56]. Moreover, F-containing aromatic ring of FLN positioned towards the narrower rim of the $\beta$-CD truncated cone, which is also observed in $2 \mathrm{D}{ }^{1} \mathrm{H}-$ ${ }^{1} \mathrm{H}$ ROESY spectrum containing the cross peak between $\mathrm{H}-1, \mathrm{H}-2$ and $\mathrm{H}-5^{\prime}$. In the other dockings conformations models, it is apparent that the phenyl ring also participates in complexation (Fig. 4). Interestingly, similar to $2 \mathrm{D}{ }^{1} \mathrm{H}-{ }^{1} \mathrm{H}$ ROESY results, the phenyl ring protrudes on the opening of the narrower rim side of the $\beta-C D$ cavity (Fig. 4b, f, h). The docking binding affinity for the best energy minimized $\beta$-CD:FLN complex was obtained to be $-5.4 \mathrm{kcal} \mathrm{mol}^{-1}$, which is favourable for such type of complex [50]. The ensemble of all possible computational docking conformations of $\beta$-CD:FLN complex is shown in Additional file 1: Figure S2. Based on molecular docking studies performed, it is apparent that all aromatic rings dock into the $\beta$-CD cavity but F-containing aromatic ring participates more favourably than the phenyl ring.

\section{${ }^{1} \mathrm{H}$ NMR spectral assignments and chemical shift change data of $\beta-C D$}

The assignment of the $\beta-C D$ protons, in the spectra of $\beta-C D$ and FLN mixture, was made with the help of their ${ }^{1} \mathrm{H}$ signals and $2 \mathrm{D}^{1} \mathrm{H}_{-}{ }^{1} \mathrm{H}$ COSY spectral data [47]. Expansion of $2 \mathrm{D}^{1} \mathrm{H}^{-1} \mathrm{H}$ COSY spectrum of an FLN: $\beta-\mathrm{CD}$ mixture showing $\beta-C D$ regions are shown in Additional

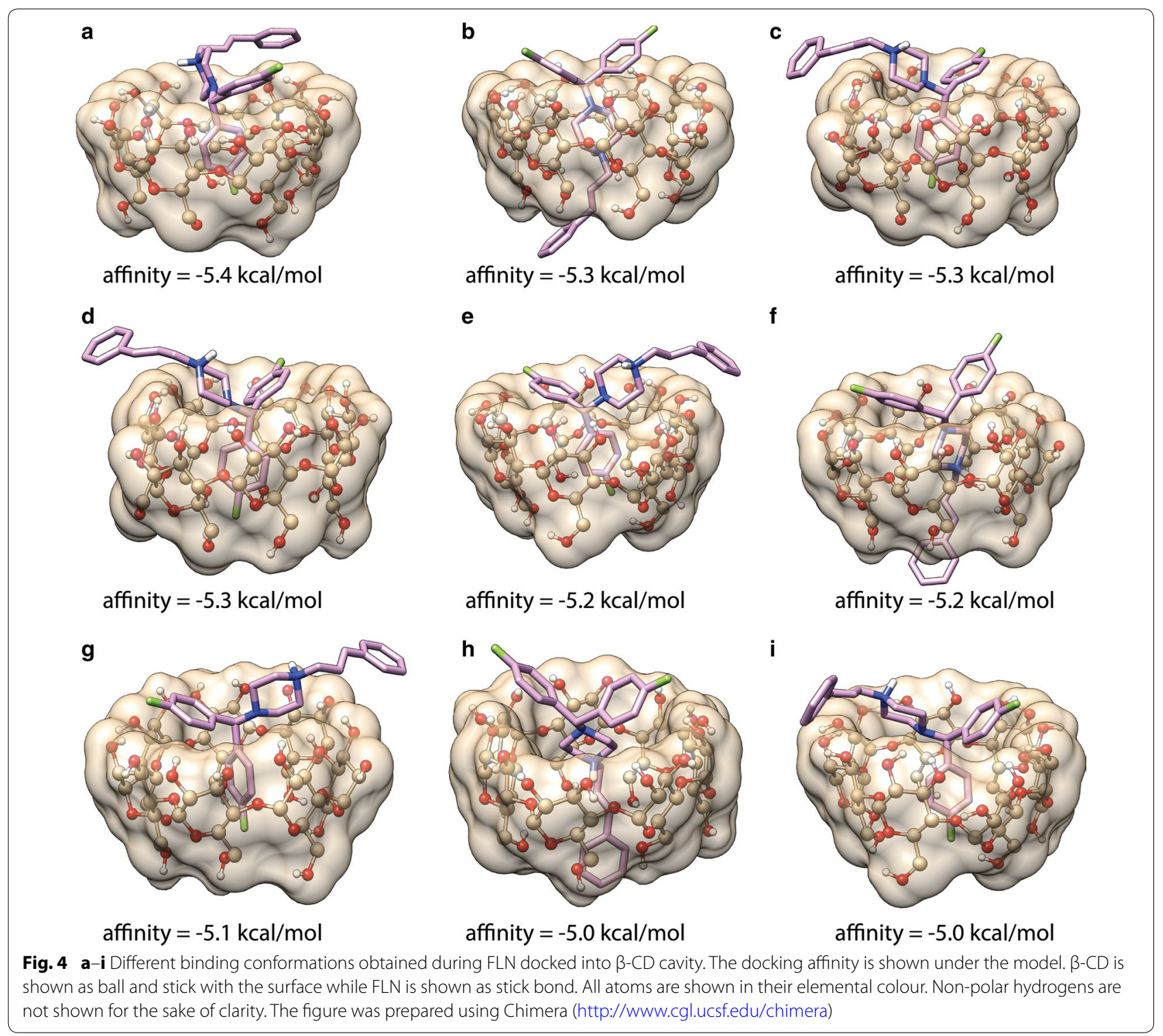




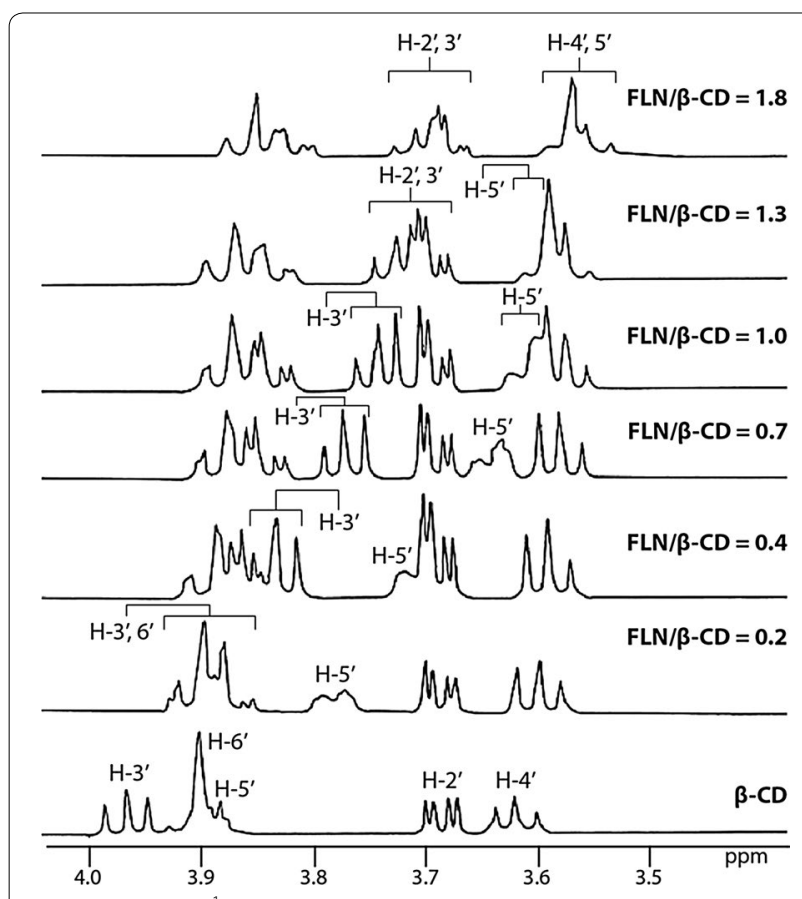

Fig. 5 A part of ${ }^{1} H$ NMR spectra $(500 \mathrm{MHz})$ showing protons of $\beta-C D$ in the absence, as well as in the presence, of varying amount of FLN

file 1: Figure S3. On the investigation of ${ }^{1} \mathrm{H}$ NMR spectra of mixtures of $\beta-C D$ and FLN, an upfield shift in $\mathrm{H}-3^{\prime}$ and $\mathrm{H}-5^{\prime}$ (located inside the central cavity) signals of $\beta-\mathrm{CD}$ was observed $[47,50-52,56]$. Other $\beta-\mathrm{CD}$ signals $\left(\mathrm{H}-1^{\prime}\right.$, $\left.2^{\prime}, 4^{\prime}, 6^{\prime}\right)$ also exhibited shift changes but these were negligible compared to $\mathrm{H}-3^{\prime}$ and $\mathrm{H}-5^{\prime}$. In the presence of FLN, $\Delta \delta$ for $\mathrm{H}-5^{\prime}$ were more pronounced than those of $\mathrm{H}-3^{\prime}$ signal of $\beta-\mathrm{CD}$.

The upfield shift of ${ }^{1} \mathrm{H}$ signals located inside the cavity, namely $\mathrm{H}-3^{\prime}$ and $\mathrm{H}-5^{\prime}$, have been attributed to the magnetic anisotropy effect in the $\beta$-CD cavity due to the inclusion of groups rich in $\pi$-electrons [51]. The continuous upfield shift changes of ${ }^{1} \mathrm{H}$ signals observed in $\mathrm{H}-3^{\prime}$ and $\mathrm{H}-5^{\prime}$ of $\beta-\mathrm{CD}$ in the ${ }^{1} \mathrm{H}$ NMR spectra of $\beta$-CDFLN mixtures thus confirm the formation of the inclusion complex between $\beta-C D$ and FLN $[47,50-52,56]$.
Expansions of part of ${ }^{1} \mathrm{H}$ NMR spectra of pure $\beta$-CD and mixture of $\beta-C D$ and FLN in varying amounts of FLN are displayed in Fig. 5 and their $\Delta \delta$ data are listed in Table 1.

\section{${ }^{1} \mathrm{H}$ NMR spectral assignments and chemical shift change data of FLN}

The resonance assignment of guest FLN aromatic ring protons in the free as well as host $\beta$-CD bound state were achieved using ${ }^{1} \mathrm{H}$ NMR as well as $2 \mathrm{D}{ }^{1} \mathrm{H}-{ }^{1} \mathrm{H}$ COSY spectral data. Part of the $2 \mathrm{D}{ }^{1} \mathrm{H}-{ }^{1} \mathrm{H}$ COSY spectrum of the mixture of $\beta-C D$ and FLN displaying through bond cross connection peaks between aromatic protons of FLN is shown in Fig. 6.

The aromatic protons were observed as three signals, a triplet at $7.20 \mathrm{ppm}$ integrating for four protons, a multiplet at $7.45 \mathrm{ppm}$ for three protons and a multiplet at $7.58 \mathrm{ppm}$ for six protons. Fluorine has a slight 'donor substituent' effect in the benzene ring. For instance, ortho-, meta-, and para-proton signals of fluorobenzene appear at $6.99,7.24$ and $7.08 \mathrm{ppm}$, respectively. In styrene, ortho, meta and para protons are increasingly shielded. In order to elucidate the question on $\mathrm{H}-1$ and $\mathrm{H}-2$ assignment, we examined for intramolecular NOE cross peaks between $\mathrm{H}-2$ and $\mathrm{H}-3$ in ${ }^{1} \mathrm{H}-{ }^{1} \mathrm{H}$ ROESY spectrum. The triplet at $7.20 \mathrm{ppm}(J=8.6 \mathrm{~Hz})$ was assigned to $\mathrm{H}-1$ protons and it showed the ${ }^{1} \mathrm{H}-{ }^{1} \mathrm{H}$ COSY interaction with the multiplet at $7.58 \mathrm{ppm}$, which was ascribed to $\mathrm{H}-9$ and $\mathrm{H}-2$ protons. The observed shape of $\mathrm{H}-1$ and $\mathrm{H}-2$ (like triplets) are undoubtedly from ${ }^{1} \mathrm{H}_{-}{ }^{19} \mathrm{~F}$ cross coupling interactions. It is well known that, for fluorobenzene derivatives, the coupling constants $3 J(\mathrm{H}, \mathrm{F})=6.2-10.1 \mathrm{~Hz}$ and $4 J(\mathrm{H}$, F) $=6.2-8.3 \mathrm{~Hz}$. The multiplet at $7.45 \mathrm{ppm}$ was due to $\mathrm{H}-10,11$ protons. In FLN: $\beta-C D$ mixtures, the signal for $\mathrm{H}-2$ and $\mathrm{H}-9$ separated and the nature of $\mathrm{H}-2$ resembles a triplet. A doublet at $6.97 \mathrm{ppm}(J=16.0 \mathrm{~Hz})$, which appeared in the aromatic region was ascribed to $\mathrm{H}-8$, while the $\mathrm{H}-7$ was found resonating as a merged doublet of the triplet at $6.32 \mathrm{ppm}$.

The aromatic protons of FLN were deshielded and pattern of their ${ }^{1} \mathrm{H}$ NMR peaks splitting in presence of $\beta-\mathrm{CD}$ suggests some chiral differentiation of guest FLN by

Table $1{ }^{1} \mathrm{H}$ NMR $(500 \mathrm{MHz})$ chemical shift change $(\Delta \delta)$ data for the $\beta$-CD protons in the presence of FLN

\begin{tabular}{|c|c|c|c|c|c|c|}
\hline$[F L N] /[\beta-C D]$ & $\mathrm{H}-\mathbf{1}^{\prime}$ & $\mathrm{H}-\mathbf{2}^{\prime}$ & $\mathrm{H}-3^{\prime}$ & $\mathrm{H}-\mathbf{4}^{\prime}$ & $\mathrm{H}-5^{\prime}$ & $\mathrm{H}-\mathbf{6}^{\prime}$ \\
\hline 0.2 & -0.056 & -0.001 & -0.105 & -0.022 & -0.117 & -0.009 \\
\hline 0.4 & -0.067 & -0.003 & -0.157 & -0.033 & -0.184 & -0.019 \\
\hline 0.7 & -0.078 & -0.005 & -0.203 & -0.043 & -0.239 & -0.045 \\
\hline 1.0 & -0.084 & -0.008 & -0.227 & -0.058 & -0.275 & -0.052 \\
\hline 1.3 & -0.086 & -0.011 & -0.244 & -0.060 & -0.294 & -0.053 \\
\hline 1.8 & -0.088 & -0.007 & -0.258 & -0.062 & -0.319 & -0.057 \\
\hline
\end{tabular}

Negative values indicate upfield shift changes 
host $\beta$-CD $[48,49]$. The ${ }^{1} \mathrm{H}$ NMR signal for $\mathrm{H}-9,2$ which appeared as a merged signal in the spectrum of unbound FLN, separated in the spectra of some FLN: $\beta-C D$ mixtures. The ${ }^{1} \mathrm{H} N M R$ spectra of expanded aromatic regions of guest FLN in the bound as well as unbound with host $\beta-C D$ is shown in Additional file 1: Figure S4. The ${ }^{1} \mathrm{H}$ NMR shielding and deshielding pattern of $\beta-C D$ and FLN protons in the bound state indicate the involvement of aromatic ring group in complexation [47] but the identity of the aromatic rings penetrating into $\beta-C D$ cavity could not be achieved and therefore further studies were required. Two-dimensional ${ }^{1} \mathrm{H}_{-}{ }^{1} \mathrm{H}$ ROESY and molecular docking studies further applied to understand $\beta$-CDFLN inclusion complex structure (see " $2 \mathrm{D}^{1} \mathrm{H}_{-}{ }^{1} \mathrm{H}$ ROESY spectrum of $\beta-C D-F L N$ mixture and structure of the $\beta$-CD-FLN inclusion complex by NMR and molecular docking approach" section).

\section{Stoichiometry and association constant of $\beta-C D-F L N$ complex}

Next, we wanted to determine the stoichiometry, association constant $\left(K_{\mathrm{a}}\right)$ and the Gibb's free energy $(\Delta \mathrm{G})$ of the $\beta$-CD-FLN inclusion complex. The stoichiometry and $K_{\mathrm{a}}$ of the $\beta$-CD-FLN complex were established with the help of the Scott's method [57]. In Scott's equation,

$$
[\mathrm{FLN}]_{\mathrm{t}} / \Delta \delta_{\mathrm{obs}}=[\mathrm{FLN}]_{\mathrm{t}} / \Delta \delta_{\mathrm{c}}+1 / K_{\mathrm{a}} \Delta \delta_{\mathrm{c}}
$$

where $[\mathrm{FLN}]_{\mathrm{t}}$ is the molar concentration of the guest, $\Delta \delta_{\text {obs }}$ the observed chemical shift change for a given $[\mathrm{FLN}]_{\mathrm{t}}$ concentration, $\Delta \delta_{\mathrm{c}}$ the chemical shift change between a pure sample of complex and the free component at the saturation. The plot of $\Delta \delta$ for the $\beta$-CD protons $\left(\mathrm{H}-3^{\prime}\right.$ and $\left.\mathrm{H}-5^{\prime}\right)$ against [FLN] in the form of [FLN]/ $\Delta \delta_{\text {obs }}$ versus [FLN] appeared to be linear fits (Fig. 7) suggesting 1:1 stoichiometry for the $\beta$-CD-FLN inclusion complex. The slope of the plot (Fig. 7) is thus equal to $1 /$ $\Delta \delta_{\mathrm{c}}$ and the intercept with the vertical axis to $1 / K_{\mathrm{a}} \Delta \delta_{\mathrm{c}}$ allowing the estimation of $K_{\mathrm{a}}$ to be $157 \mathrm{M}^{-1}$, which is the average of two $K_{\mathrm{a}}$.

We were also interested to probe the differences between binding constants of two nearly similar structures. The binding constant of $\beta-\mathrm{CD}-\mathrm{CTZ}$ complex was reported earlier to be $70 \mathrm{M}^{-1}$ [56], which is nearly half of the binding constant calculated for $\beta$-CD-FLN complex. This could be due to the structural differences between CTZ and FLN. The $\Delta G$ associated during $\beta-C D$ and FLN inclusion complex was calculated using standard Eq. (2):

$$
\Delta \mathrm{G}=-\mathrm{RT} \ln K_{a}
$$

where $\mathrm{R}$ is the universal gas constant $\left(\mathrm{J} \mathrm{mol}^{-1} \mathrm{~K}^{-1}\right), \mathrm{T}$ is temperature (Kelvin) and $K_{a}$ is the binding constant. The $\Delta \mathrm{G}$ value was calculated to be $-12.65 \mathrm{~kJ} \mathrm{~mol}^{-1}$.

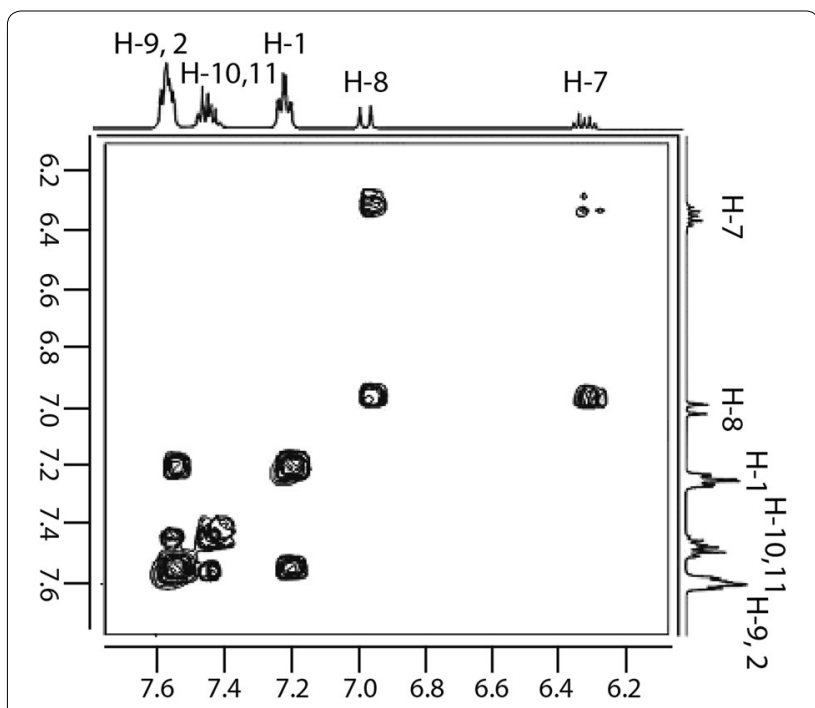

Fig. 6 Part of the $2 \mathrm{D}^{1} \mathrm{H}-{ }^{1} \mathrm{H}$ COSY spectrum $(500 \mathrm{MHz})$ of a mixture of $\beta-C D$ and FLN, displaying through the bond interaction of aromatic protons of FLN

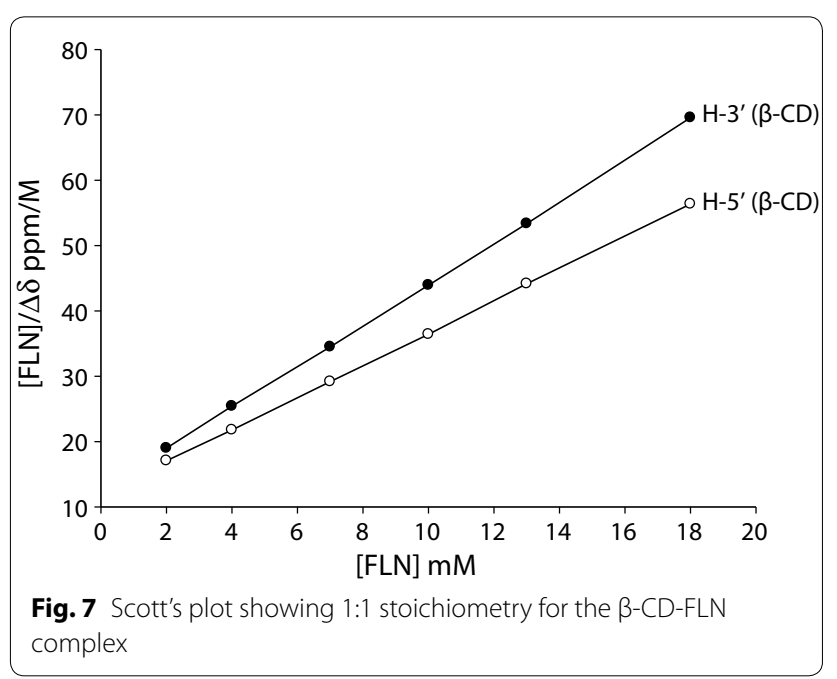

\section{Conclusions}

The ${ }^{1} \mathrm{H}$ NMR spectral data of pure FLN, pure $\beta-C D$ and mixtures of $\beta-C D$ and FLN in $D_{2} \mathrm{O}$ confirmed the complexation between $\beta$-CD and FLN. The ${ }^{1} \mathrm{H}$ NMR together with $2 \mathrm{D}{ }^{1} \mathrm{H}^{-}{ }^{1} \mathrm{H}$ COSY spectral data provided the resonance assignment of host and guest molecules. The stoichiometry, association constant and the Gibb's free energy were determined using ${ }^{1} \mathrm{H}$ NMR titration data. Two-dimensional ${ }^{1} \mathrm{H}_{-}{ }^{1} \mathrm{H}$ ROESY spectral data together with computational molecular docking simulation studies confirmed that F-substituted aromatic ring of guest penetrates into the host $\beta$-CD cavity from the wider rim side. The tail end aromatic rings of guest FLN were proximal near to narrower rim side of truncated host $\beta-C D$ 
cone. The splitting of the most of the aromatic ring protons of the FLN, in the presence of $\beta-C D$, suggests some chiral differentiation of guest FLN by host $\beta-C D$. The structural studies of FLN- $\beta-C D$ inclusion complex may open new avenues for new drug formulation in the pharmaceutical industry.

\section{Additional file}

Additional file 1: Figure S1: Full $2 \mathrm{D}^{1} \mathrm{H}-{ }^{1} \mathrm{H}$ ROESY spectrum $(500 \mathrm{MHz})$ showing through space cross correlation peaks between $\beta$-CD protons and aromatic rings proton of FLN. Figure S2. Ensemble of different conformations obtained during FLN docked into $\beta$-CD cavity. The best docking conformation model shown as bond while other docking conformation modes are shown as wire frame. All atoms are shown in their elemental colour ( $\beta-C D$ and best docking conformer). The inclusion of guest FLN was from the wide rime side during all docking simulations performed. The phenyl ring of FLN are close to the narrow rim in some docking conformations. $\beta-C D$ shown as ball and stick with surface while FLN shown as stick/wire bond. Non-polar hydrogens are not shown for sake of clarity. The figure was prepared using Chimera (http://www. cgl.ucsf.edu/chimera). Figure S3. Expanded region of $2 \mathrm{D}^{1} \mathrm{H}-{ }^{1} \mathrm{H}$ COSY spectrum $(500 \mathrm{MHz})$ of FLN: $\beta-C D$ mixture showing $\beta-\mathrm{CD}$ region. The assignments of $\beta-\mathrm{CD}$ protons namely $\mathrm{H}-\mathbf{1}^{\prime}, \mathrm{H}-2^{\prime}, \mathrm{H}-3^{\prime}, \mathrm{H}-4^{\prime}, \mathrm{H}-5^{\prime}$ and $\mathrm{H}-6^{\prime}$ was made with the help of ${ }^{1} \mathrm{H} N \mathrm{NR}$ and $2 \mathrm{D}^{1} \mathrm{H}-{ }^{1} \mathrm{H}$ COSY cross correlation peaks. Figure S4. Expansion of part of ${ }^{1} \mathrm{H}$ NMR spectra $(500 \mathrm{MHz})$ of FLN protons in the presence, as well as in the absence, of $\beta-C D$.

\section{Authors' Contributions}

SKU and SMA conceived the study and designed the experiments. SKU analysed the NMR and computational docking data. SKU and SMA wrote the manuscript. Both authors read and approved the final manuscript.

\section{Acknowledgements}

SKU is currently funded (DST INSPIRE Faculty Award) by the Department of Science \& Technology, Govt. of India. SKU thanks to Dr. Souvik Maiti for continuous support and Dr. S. Ramachandran for critical reading of the manuscript.

\section{Competing interests}

The authors declare that they have no competing interests.

\section{Ethics approval and consent to participate}

Not applicable.

\section{Publisher's Note}

Springer Nature remains neutral with regard to jurisdictional claims in published maps and institutional affiliations.

Received: 29 September 2017 Accepted: 28 February 2018 Published online: 28 March 2018

\section{References}

1. Holmes B, Brogden RN, Heel RC, Speight TM, Avery GS (1984) Flunarizine. A review of its pharmacodynamic and pharmacokinetic properties and therapeutic use. Drugs 27:6-44. https://doi. org/10.2165/00003495-198427010-00002

2. Perin PM, Haid S, Brown RJP, Doerrbecker J, Schulze K, Zeilinger C, von Schaewen M, Heller B, Vercauteren K, Luxenburger E, Baktash YM, Vondran FWR, Speerstra S, Awadh A, Mukhtarov F, Schang LM, Kirschning A, Müller R, Guzman CA, Kaderali L, Randall G, Meuleman P, Ploss A, Pietschmann T (2016) Flunarizine prevents hepatitis $C$ virus membrane fusion in a genotype-dependent manner by targeting the potential fusion peptide within E1. Hepatology 63:49-62. https://doi.org/10.1002/ hep.28111

3. Retzlaff J, Thamm K, Ghosh CC, Ziegler W, Haller H, Parikh SM, David S (2017) Flunarizine suppresses endothelial angiopoietin-2 in a calciumdependent fashion in sepsis. Sci Rep 7:44113. https://doi.org/10.1038/ srep44113

4. Prigozhin DM, Modis Y (2016) Flunarizine arrests hepatitis C virus membrane fusion. Hepatology 63:14-16. https://doi.org/10.1002/hep.28224

5. Szejtli J (1998) Introduction and general overview of cyclodextrin chemistry. Chem Rev 98:1743-1754. https://doi.org/10.1021/cr970022c

6. Crini G (2014) Review: a history of cyclodextrins. Chem Rev 114:1094010975. https://doi.org/10.1021/cr500081p

7. Steed JW, Atwood JL (2009) Molecular guests in solution. In: Supramolecular chemistry, 2nd ed.; Wiley, London, Chapter 6, p 307

8. Harada A, Takashima Y, Yamaguchi H (2009) Cyclodextrin-based supramolecular polymers. Chem Soc Rev 38:875-882. https://doi.org/10.1039/ b705458k

9. Hapiot F, Tilloy S, Monflier E (2006) Cyclodextrins as supramolecular hosts for organometallic complexes. Chem Rev 106:767-781. https://doi. org/10.1021/cr050576c

10. Morillo E (2006) Application of cyclodextrins in agrochemistry. In: Dodziuk H (ed) Cyclodextrins and their complexes. Chemistry. Analytical methods, applications, Chapter 16. Wiley-VCH, Verlag GmbH \& Co. KGaA, Weinheim, p 459

11. Faugeras $\mathrm{P}-\mathrm{A}$, Boëns $\mathrm{B}$, Elchinger $\mathrm{P}-\mathrm{H}$, Brouillette $\mathrm{F}$, Montplaisir $\mathrm{D}$, Zerrouki R, Lucas R (2012) When cyclodextrins meet click chemistry. Eur J Org Chem 2012:4087-4105. https://doi.org/10.1002/ejoc.201200013

12. Li S, Purdy WC (1992) Cyclodextrins and their applications in analytical chemistry. Chem Rev 92:1457-1470. https://doi.org/10.1021/cr00014a009

13. Hinze WL (1981) Applications of cyclodextrins in chromatographic separations and purification methods. Sep Purif Methods 10:159-237. https:// doi.org/10.1080/03602548108066011

14. Xiao Y, Ng S-C, Tan TTY, Wang Y (2012) Recent development of cyclodextrin chiral stationary phases and their applications in chromatography. J Chromatogr A 1269:52-68. https://doi.org/10.1016/j.chroma.2012.08.049

15. Dodziuk H (2006) Cyclodextrins and their complexes. Chemistry. Analytical methods, applications. Wiley-VCH, Verlag GmbH \& Co. KGaA, Weinheim

16. Astray G, Gonzalez-Barreiro C, Mejuto JC, Rial-Otero R, Simal-Gándara J (2009) A review on the use of cyclodextrins in foods. Food Hydrocolloids 23:1631-1640. https://doi.org/10.1016/j.foodhyd.2009.01.001

17. Komiyama M, Monflier E (2006) Cyclodextrin catalysis. In: Dodziuk H (ed) Cyclodextrins and their complexes. Chemistry, analytical methods, applications, Chapter 4. Wiley-VCH, Verlag GmbH \& Co. KGaA, Weinheim, p 93

18. Bai CC, Tian BR, Zhao T, Huang Q, Wang ZZ (2017) Cyclodextrin-catalyzed organic synthesis: reactions, mechanisms, and applications. Molecules 22:1475. https://doi.org/10.3390/molecules22091475

19. Trotta F (2016) Cyclodextrin in membranes. In: Drioli E, Giorno L (eds) Encyclopedia of membranes. Springer, Berlin. https://doi. org/10.1007/978-3-662-44324-8_2044

20. Buschmann H-J, Knittel D, Schollmeyer E (2001) New textile applications of cyclodextrins. J Incl Phenom Macrocycl Chem 40:169-172. https://doi. org/10.1023/A:1011892600388

21. Buschmann HJ, Schollmeyer E (2002) Applications of cyclodextrins in cosmetic products: a review. J Cosmet Sci 53:185-191

22. Bilensoy E (ed) (2011) Cyclodextrins in pharmaceutics, cosmetics, and biomedicine: current and future industrial applications. Wiley, Hoboken, USA

23. Marques HMC (2011) A review on cyclodextrin encapsulation of essential oils and volatiles. Flavour Fragr J 25:313-326. http://dx.doi.org/10.1002/ ff. 2019

24. Kant A, Linforth RS, Hort J, Taylor AJ (2004) Effect of $\beta$-cyclodextrin on aroma release and flavor perception. J Agric Food Chem 52:2028-2035. https://doi.org/10.1021/jf0307088

25. Villalonga R, Cao R, Fragoso A (2007) Supramolecular chemistry of cyclodextrins in enzyme technology. Chem Rev 107:3088-3116. https://doi. org/10.1021/cr050253g

26. Zhang J, Ma PX (2013) Cyclodextrin-based supramolecular systems for drug delivery: recent progress and future perspective. Adv Drug Deliv Rev 65:1215-1233. https://doi.org/10.1016/j.addr.2013.05.001 
27. Alvarez-Lorenzo C, García-González CA, Concheiro A (2017) Cyclodextrins as versatile building blocks for regenerative medicine. J Control Release 268:269-281. https://doi.org/10.1016/j.jconrel.2017.10.038

28. van de Manakker F, Vermonden T, van Nostrum CF, Hennink WE (2009) Cyclodextrin-based polymeric materials: synthesis, properties, and pharmaceutical/biomedical applications. Biomacromolecules 10:3157-3175. https://doi.org/10.1021/bm901065f

29. Guo R, Wilson LD (2013) Cyclodextrin-based microcapsule materials - their preparation and physiochemical properties. Curr Org Chem 17:14-21. https://doi.org/10.2174/138527213805289204

30. Varan G, Varan C, Erdoğar N, Hıncal AA, Bilensoy E (2017) Amphiphilic cyclodextrin nanoparticles. Int J Pharm 531:457-469. https://doi. org/10.1016/j.ijpharm.2017.06.010

31. Mejia-Ariza R, Graña-Suárez L, Verboom W, Huskens J (2017) Cyclodextrinbased supramolecular nanoparticles for biomedical applications. J Mater Chem B 5:36-52. https://doi.org/10.1039/C6TB02776H

32. Adeoye O, Cabral-Marques H (2017) Cyclodextrin nanosystems in oral drug delivery: a mini review. Int J Pharm 531:521-531. https://doi. org/10.1016/j.jpharm.2017.04.050

33. Trotta F, Zanetti M, Cavalli R (2012) Cyclodextrin-based nanosponges as drug carriers. Beilstein J Org Chem 8:2091-2099. https://doi.org/10.3762/ bjoc.8.235

34. Landy D, Mallard I, Ponchel A, Monflier E, Fourmentin S (2012) Cyclodextrins for remediation technologies. In: Lichtfouse E, Schwarzbauer J, Robert D (eds) Environmental chemistry for a sustainable world. Springer, Dordrecht. https://doi.org/10.1007/978-94-007-2442-6_2

35. Morin-Crini N, Crini G (2013) Environmental applications of waterinsoluble $\beta$-cyclodextrin-epichlorohydrin polymers. Prog Polym Sci 38:344-368. https://doi.org/10.1016/j.progpolymsci.2012.06.005

36. Szejtli J (1990) The cyclodextrins and their applications in biotechnology. Carbohydr Polym 12:375-392. https://doi. org/10.1016/0144-8617(90)90088-A

37. Amiri S, Amiri S (2017) Cyclodextrins: properties and industrial applications. Wiley, Chichester

38. Sliwa W, Girek T (eds) (2017) Cyclodextrins: properties and applications. Wiley-VCH Verlag GmbH \& Co. KGaA, Weinheim

39. Hedges AR (1998) Industrial applications of cyclodextrins. Chem Rev 98:2035-2044. https://doi.org/10.1021/cr970014w

40. Heath JR (2015) Nanotechnologies for biomedical science and translational medicine. Proc Natl Acad Sci USA 112:14436-14443. https://doi. org/10.1073/pnas.1515202112

41. Uekama K, Hirayama F, Irie T (1998) Cyclodextrin drug carrier systems. Chem Rev 98:2045-2076. https://doi.org/10.1021/cr970025p

42. Davis ME, Brewster ME (2004) Cyclodextrin-based pharmaceutics: past, present and future. Nat Rev Drug Discov 3:1023-1035. https://doi. org/10.1038/nrd1576

43. Loftsson T, Duchêne D (2007) Cyclodextrins and their pharmaceutical applications. Int J Pharm 329:1-11. https://doi.org/10.1016/j. ijpharm.2006.10.044
44. Del Valle EEM (2004) Cyclodextrins and their uses: a review. Process Biochem 39:1033-1046. https://doi.org/10.1016/S0032-9592(03)00258-9

45. Serno T, Geidobler R, Winter G (2011) Protein stabilization by cyclodextrins in the liquid and dried state. Adv Drug Deliv Rev 3:1086-1106. https://doi.org/10.1016/j.addr.2011.08.003

46. Noël S, Léger B, Ponchel A, Philippot K, Denicourt-Nowicki A, Roucoux A, Monflier E (2014) Cyclodextrin-based systems for the stabilization of metallic(0) nanoparticles and their versatile applications in catalysis. Catal Today 235:20-32. https://doi.org/10.1016/j.cattod.2014.03.030

47. Schneider H-J, Hacket F, Rüdiger V, Ikeda H (1998) NMR studies of cyclodextrins and cyclodextrin complexes. Chem Rev 98:1755-1786. https:// doi.org/10.1021/cr970019t

48. Kitae T, Nakayama T, Kano K (1998) Chiral recognition of a-amino acids by charged cyclodextrins through cooperative effects of Coulomb interaction and inclusion. J Chem Soc Perkin Trans 2:207-212. doi: https://dx.doi. org/10.1039/A706479|

49. Dodziuk H, Koźmiński W, Ejchart A (2004) NMR studies of chiral recognition by cyclodextrins. Chirality 16:90-105. https://doi.org/10.1002/ chir.10304

50. Maheshwari A, Saraswat H, Upadhyay SK (2017) Structural insights into the inclusion complexes between clomiphene citrate and $\beta$-cyclodextrin: the mechanism of preferential isomeric selection. Chirality 29:451-457. https://doi.org/10.1002/chir.22712

51. Upadhyay SK, Kumar G (2009) NMR and molecular modelling studies on the interaction of fluconazole with $\beta$-cyclodextrin. Chem Cent J 3:9. https://doi.org/10.1186/1752-153X-3-9

52. Ali SM, Upadhyay SK (2008) Complexation study of midazolam hydrochloride with $\beta$-cyclodextrin: NMR spectroscopic study in solution. Magn Reson Chem 46:676-679. https://doi.org/10.1002/mrc.2231

53. Trott O, Olson AJ (2010) AutoDock Vina: improving the speed and accuracy of docking with a new scoring function, efficient optimization and multithreading. J Comput Chem 31:455-461. https://doi.org/10.1002/ jcc.21334

54. Irwin JJ, Sterling T, Mysinger MM, Bolstad ES, Coleman RG (2012) ZINC: a free tool to discover chemistry for biology. J Chem Inf Model 52:17571768. https://doi.org/10.1021/ci3001277

55. Maheshwari A, Sharma D (2010) A comparative study of inclusion complexes of flunarizine with alpha ( $a-C D)$ and beta-cyclodextrin $(\beta-C D)$. J Incl Phenom Macrocycl Chem 68:453-459. https://doi.org/10.1007/ s10847-010-9809-1

56. Ali SM, Upadhyay SK, Maheshwari A (2007) NMR spectroscopic study of inclusion complexes of cetirizine dihydrochloride and $\beta$-cyclodextrin in solution. Spectroscopy 21:177-182. https://doi.org/10.1155/2007/796821

57. Scott RL (1956) Some comments on the Benesi-Hildebrand equation. Recl Trav Chim Pays-Bas 75:787-789. https://doi.org/10.1002/ recl. 19560750711

\section{Submit your manuscript to a SpringerOpen ${ }^{\circ}$ journal and benefit from:}

- Convenient online submission

- Rigorous peer review

- Open access: articles freely available online

- High visibility within the field

Retaining the copyright to your article

Submit your next manuscript at springeropen.com 